\title{
Interpreting the World Health Assembly Targets on Exclusive Breastfeeding by 2025: What is expected of each country?
}

\author{
Dr. Arun Gupta* \\ Dr. JP Dadhich* \\ Patti Rundall** \\ Nupur Bidla* \\ * Breastfeeding Promotion Network of India (BPNI)/International Baby Food Action \\ Network (IBFAN), South Asia \\ ** Baby Milk Action, UK
}

\section{Corresponding Author:}

Dr. JP Dadhich

National Coordinator and Technical Director,

Breastfeeding Promotion Network of India (BPNI),

BP-33, Pitampura, Delhi

Email: jpdadhich@bpni.org 
The World Health Assembly resolution 65.6 in 2012 identified six nutrition targets to be achieved by 2025. One of these targets is to increase the global rate of exclusive breastfeeding during the first 6 months to at least 50\% from the prevailing rate of $38 \%$ in 2012 (WHO/UNICEF, 2014). Most countries are expected to increase their exclusive breastfeeding rates to achieve this target.

This brief helps interpret WHA target for countries. Countries already at or near 50\% exclusive breastfeeding should also contribute to World Health Assembly targets and continue to strive for improvements because of the health and economic benefits of exclusive breastfeeding.

WHO suggests, "Countries can adopt the global targets as their national ones but can also choose a different target given the country context” (WHO, 2016) and suggests a minimum increase of $1.2 \%$ per year or more (WHO/UNICEF, 2014). The Joint WHO-UNICEF Technical Expert Advisory Group on Nutrition Monitoring recommended that the countrylevel targets were calculated based on the rates of non-exclusive breastfeeding $(\mathrm{NEBF}=100-\mathrm{EBF})$. At global level, the WHA target would require a $30 \%$ reduction in the NEBF. For this reduction over 13 years (between 2012 and 2025), a yearly relative reduction rate of $\approx 2.74 \%$ was proposed. Logically, to achieve this target, all countries should reduce the NEBF rates by $30 \%$ and thereby contribute to achieve the global target of reducing NEBF from $62 \%$ to $50 \%$.

In 2014, WHO provided a tool to help countries to set their national targets and track the progress on exclusive breastfeeding (WHO, 2019). The tracking tool calculates the required Annual Average Rate of Reduction (AARR) for 'non-exclusive breastfeeding' (NEBF). The tool provides the specific requirement of each country, which is aligned with the global target. This ensures that a country is reducing NEBF (and increasing EBF rates) at least as fast as the world must reduce it (WHO, 2016).

The Global Nutrition Report 2018 (Global nutrition report, 2018) tracks the global target for exclusive breastfeeding for a country by taking the prescribed global AARR of 2.74 of not exclusively breastfed (NEBF). It considered a country on track if the AARR for NEBF was $\geq 2.74$; off track (some progress) if NEBF rate was between $\geq 0.8-2.74$ and off track (no progress or worsening) if NEBF rate was $<0.8$. The report found that out of 194 countries analysed, only 31 were on track for achieving the exclusive breastfeeding target.

\section{Different Interpretations the WHA Target on Exclusive Breastfeeding}

The following five examples illustrate that there appears to be widespread misunderstanding of the global target, with some people assuming that $50 \%$ is enough at national level and those countries which have achieved 50\% need not contribute/improve, and the other that this target is the optimum instead of an interim target:

1. Two years ago, at an Indian malnutrition conference, one researcher said that India has already achieved its WHA target, given that there are many States where 
exclusive breastfeeding rates were more than 50\% implying that those States need not make efforts.

2. Alive and Thrive has recently launched a tool to estimate cost of inadequate breastfeeding. The following statement appears on the India country page: "Globally, the World Health Assembly (WHA) has set a target to increase the exclusive breastfeeding rate to $50 \%$ by 2025 . By the time these targets were set in 2012, India was well on its way to reaching a national exclusive breastfeeding rate of 50\%” (Alive and Thrive, 2019).

3. In its Multi-sector Nutrition Plan (2018-2022), Nepal seemed to be satisfied having achieved the target. As Nepal's exclusive breastfeeding rate is 66\%. ".... The childhood overweight and breastfeeding targets have been achieved and efforts need accelerating to achieve the other targets" (National planning commission Nepal, 2018).

4. The World Bank's investment framework for meeting the global nutrition target for breastfeeding" states, "However, rates of exclusive breast- feeding in some regions-South Asia and Eastern and Southern Africa for example-have increased since the year 2000 and now surpass the 50 percent target” (Dylan W, Eberwein JD, Sullivan L et al, 2017)

5. A recent tweet of the Global Nutrition report made a similar statement that India has already achieved the World Health Assembly target, implying that little additional effort was needed.

\section{A tool to estimate targets}

We have developed an MS Excel based tool and used it to project the targets in 130 countries using updated information on rates of exclusive breastfeeding. The tool can be used to calculate projected targets in any country. Click here to download:

https://www.worldbreastfeedingtrends.org/uploads/resources/document/tool-forcalculation-of-expected-exclusive-breastfeeding-rates-by-2025.xlsx

\section{Conclusion and recommendation}

Given the misinterpretation of the targets, there is risk of losing or wasting opportunities for further improvements in the protection, promotion and support of breastfeeding. Such an interpretation could halt progress in countries that have already achieved the $50 \%$ target. Therefore, a clear and correct interpretation of the targets and the need for every country to understand that each has to contribute to the World Health Assembly target as well as continue striving for further improvement, is necessary.

\section{We, therefore recommend:}

1. WHO and UNICEF should clarify to countries that by making use of the 'What-if' option on the tracking tool, they should opt for a minimum AARR of 2.74 to continue improvement by 2025.

2. Countries should use the tool for correct estimation of the projected targets of rate of exclusive breastfeeding by 2025. 


\section{References}

Alive and Thrive (2019). The cost of not breastfeeding tool - India. Available at: https://www.aliveandthrive.org/country-stat/india/

Dylan W, Eberwein JD, Sullivan L, et al. (2017). An Investment Framework for Meeting the Global Nutrition Target for Breastfeeding. Washington, DC: World Bank Group. Available at:

https://openknowledge.worldbank.org/bitstream/handle/10986/26069/Breast_4_web.p df?sequence $=7 \&$ isAllowed $=\mathrm{y}$

Global Nutrition Report (2018). Appendix 1: assessing country progress against global targets - a note on methodology. Available at:

https://globalnutritionreport.org/reports/global-nutrition-report-2018/appendix-1assessing-country-progress-against-global-targets-a-note-on-methodology/

National Planning Commission - Nepal (2018). Multi-sector Nutrition Plan (20182022). Available

at:http://nnfsp.gov.np/PortalContent.aspx?Doctype=Resources\&ID=330

Twitter (2019). Global nutrition report @GNReport - December 6. Available at: https://twitter.com/GNReport/status/1202704318849339392?s=20

WHO (2016). Tracking Tool - glossary and technical notes. Available at: https://www.who.int/nutrition/gtt_glossary.pdf

WHO (2019). Global targets 2025 tracking tool version 5 - 04/2019. Available at: https://extranet.who.int/sree/Reports?op=vs\&path=\%2FWHO_HQ_Reports/G16/PR OD/EXT/Targets_Menu\&VSPARAM_varLanguage=E\&VSPARAM_varISOCODE =ALB

WHO/UNICEF. (2014) Global nutrition targets 2025: breastfeeding policy brief (WHO/NMH/NHD/14.7). Geneva: World Health Organization; 2014. Available at: https://apps.who.int/iris/bitstream/handle/10665/149022/WHO_NMH_NHD_14.7_en g.pdf?ua=1 